University of Wollongong

Research Online

Faculty of Social Sciences - Papers (Archive) Faculty of Arts, Social Sciences \& Humanities

2020

\title{
Environmental influences on children's physical activity in early childhood education and care
}

Karen L. Tonge

University of Wollongong, ktonge@uow.edu.au

Rachel A. Jones

University of Wollongong, rachelj@uow.edu.au

Anthony D. Okely

University of Wollongong, tokely@uow.edu.au

Follow this and additional works at: https://ro.uow.edu.au/sspapers

Part of the Education Commons, and the Social and Behavioral Sciences Commons

Research Online is the open access institutional repository for the University of Wollongong. For further information contact the UOW Library: research-pubs@uow.edu.au 


\title{
Environmental influences on children's physical activity in early childhood education and care
}

\author{
Abstract \\ Background: To examine the relationship between attributes of early childhood education and care \\ (ECEC) settings and children's physical activity and sedentary behavior. Methods: Cross-sectional study \\ involving 490 children aged 2-5 years from 11 ECECs. The ECEC routine, size of the outdoor environment, \\ and time spent in the outdoor environment were calculated for each center. Children's physical activity \\ and sedentary time were measured using accelerometers. Multivariate linear regressions were used to \\ examine associations of the attributes of ECEC centers with the outcome variables, adjusting for the \\ effects of center clustering and gender. Results: Children in ECECs that offered free routines (where \\ children can move freely between indoor and outdoor environments) had lower levels of sedentary time \\ $(28.27 \mathrm{~min} / \mathrm{h}$ vs $33.15 \mathrm{~min} / \mathrm{h} ; \mathrm{P}=.001)$ and spent more time in total physical activity $(7.99 \mathrm{~min} / \mathrm{h}$ vs 6.57 \\ $\mathrm{min} / \mathrm{h} ; \mathrm{P}=.008)$ and moderate- to vigorous-intensity physical activity $(9.49 \mathrm{~min} / \mathrm{h}$ vs $7.31 \mathrm{~min} / \mathrm{h} ; \mathrm{P}=.008)$. \\ Children in ECECs with an outdoor environment $>400 \mathrm{~m} 2$ had less sedentary time $(28.94 \mathrm{~min} / \mathrm{h}$ vs 32.42 \\ $\min / \mathrm{h} ; \mathrm{P}=.012$ ) than those with areas children.

\section{Disciplines} \\ Education | Social and Behavioral Sciences

\section{Publication Details} \\ Tonge, K., Jones, R. \& Okely, A. (2020). Environmental influences on children's physical activity in early \\ childhood education and care. Journal of Physical Activity and Health, 17 (4), 423-428.
}


Title: Environmental Influences on Children's Physical Activity in Early Childhood Education and Care

Running Title: Influences of Children's Physical Activity

Manuscript Type: Original Research

Key Words: Outdoor environments, routines, preschool children

Abstract word count: 269

Manuscript word count: 3672

Date of Manuscript submission: 18/09/2019

\section{Full names of Authors}

Karen Tonge, Early Start, Faculty of Social Sciences, University of Wollongong, 2522, AUSTRALIA (ktonge@uow.edu.au)

Rachel A Jones, Early Start, Faculty of Social Sciences, University of Wollongong, 2522, AUSTRALIA (rachelj@uow.edu.au)

Anthony D Okely, Early Start, Faculty of Social Sciences, University of Wollongong, 2522, AUSTRALIA (tokely@uow.edu.au)

\section{Address correspondence to:}

Karen Tonge, Early Start, University of Wollongong, Northfields Ave, Wollongong 2520, NSW, Australia

ktonge@,uow.edu.au,61242214951 


\begin{abstract}
Background: Children's physical activity and sedentary behavior in early childhood education and care settings is influenced by a number of factors. The purpose of this study was to examine three less-studied environmental factors on children's physical activity and sedentary behavior.
\end{abstract}

Methods: A cross-sectional study ( $\mathrm{n}=490$, aged 2-5y, 11 ECECs) was completed. ECEC routine, size of the outdoor environment and time spent in the outdoor environment were calculated for each center. Children's physical activity and sedentary behavior was measured using accelerometers. A multivariate linear regression analysis examined associations of the attributes of ECEC centers (routine, time outdoors, and size of outdoor environment) with the outcome variables, adjusting for the effects of center clustering and gender.

$\underline{\text { Results: }}$ Children in centers that offered free routines (i.e., children can move freely between indoor and outdoor environments) spent significantly less time in sedentary behavior (SB) (28.27 mins/hr vs $33.15 \mathrm{mins} / \mathrm{hr} ; \mathrm{p}=0.001)$ and more time in total physical activity (TPA) (7.99mins/hr vs $6.57 \mathrm{mins} / \mathrm{hr} ; \mathrm{p}=0.008$ ) and moderate- to vigorous- activity (MVPA) (9.49mins/hr vs $7.31 \mathrm{mins} / \mathrm{hr} ; \mathrm{p}=0.008)$ than centers with structured routines. Children in centers with an outdoor environment greater than $400 \mathrm{~m}^{2}$ spent significantly less time in sedentary behavior (28.94 $\mathrm{min} / \mathrm{hr}$ vs $32.42 \mathrm{mins} / \mathrm{hr} ; \mathrm{p}=0.012)$. Although not significant, children in centers that offered $>4$ h outdoor time spent less time in SB $(29.12 \mathrm{mins} / \mathrm{hr}$ vs $32.65 \mathrm{mins} / \mathrm{hr})$ and more time in TPA $(16.79 \mathrm{mins} / \mathrm{hr}$ vs $14.39 \mathrm{mins} / \mathrm{hr})$ than those that offered less outdoor time.

Conclusion: Modifiable practices such as offering a free routine, increasing the time spent in outdoor environments and managing the available space effectively could potentially offer an 
easy and sustainable way for ECEC to promote physical activity and reduce sedentary behavior.

\section{Introduction}

High levels of physical activity and low levels of sedentary behavior are associated with many psychosocial, cognitive and physical health benefits for children under 5 years of age [1]. It is critical that positive physical activity behaviors develop in early childhood as these behaviors track into childhood and beyond, providing long-term health benefits [2].

In developed countries, a large proportion of young children attend some type of ECEC center for extended periods [3]. For example, more than half of children in the United States spend an average of 30 hours a week in childcare [4], making these important environments to support children's physical activity [5]. Young children are surprisingly inactive in these settings with several studies showing low compliance with recommended levels of physical activity and sedentary behavior $[6,7]$ according to the National Academy of Medicine Recommendations [8].

A recent systematic review reported that environmental factors, such as equipment and resources are important correlates of physical activity and sedentary behavior in ECEC centers [9]. Another study measured the physical activity of 3-4 year old children in UK preschools $(\mathrm{n}=30)$, and found that center policies and practices such as daily routines that offered active opportunities were positively associated with children's physical activity [10]. Other studies have shown that the amount of time spent in indoor and outdoor environments [11]; and the engagement of educators, such as providing physical activity programs [12] are also be associated with children's physical activity [13]. Although there is evidence that 
increased time in outdoor environments, active opportunities and educator engagement have a positive association with children's physical activity, the frequency and duration of time in outdoor environments, as well as the levels of physical activity of educators that may influence children's physical activity and sedentary behavior remains undetermined, and so further investigation is required.

Factors associated with the outdoor environment may be important, as children are typically more active in these environments [14]. The outdoor environment provides opportunities for gross motor activities that are key to developing confidence and conducive to physical activity participation [1]. Although indoor environments are also influential on children's physical activity, the affordances of the outdoor environment and the potential for higher levels of physical activity and reduced sedentary behavior in these environments can be difficult to replicate indoors [11] due to factors such as available space and design of the environment [15].

The aim of this study was to measure an aspect of ECEC centers that has not been previously examined - the influence of the center indoor/outdoor routine on children's physical activity and sedentary behavior. The facilitation of indoor and outdoor environments and the most effective implementation of them to promote children's physical activity and reduce sedentary behavior is not well known. In Australia, ECEC are regulated by a governing body, however the structure of their day is not mandated. Routines in ECEC may be free-flowing or structured. A free-flowing routine allows the children to move freely between the indoor and outdoor environment for the entire day, or an aspect of the day, compared to a structured routine where children are in either the indoor or outdoor environment, as determined by educators. Although free-flowing routines are becoming increasingly popular in Australian ECEC, many ECEC continue to provide a structured routine. Understanding the influence of 
the style of the ECEC routine is important for children's physical activity and sedentary behavior. Further, it provides a potentially modifiable approach to promoting children's physical activity and sedentary behavior in this setting.

Examining time spent outdoors, a modifiable factor for ECEC centers, and the size of the space and their relationship with children's physical activity and sedentary behavior were secondary aims of the study. Additionally, the study aims to measure children's physical activity and sedentary behavior and determine whether current recommendations for physical activity in ECEC are being achieved.

\section{Methods}

A convenience sample of 11 ECEC centers located within a $100 \mathrm{~km}$ radius of the city of Wollongong, New South Wales, Australia were recruited for the study. Data were collected between June and December 2015. ECEC centers were eligible to participate if they enrolled children aged 2-5 years, and these children had access to outdoor play spaces separate from other play spaces for younger children in the center. All children aged 2-5 years enrolled in the center, and their educators were invited to participate. The number and sequence of days, as well as the time of attendance each day was not mandated for children (although a typical pattern of enrolment for children aged 2-5 years is 2 or 3 days per week, for 6-8 hours each day). All eligible educators and parents of eligible children were provided with Participant Information sheets and Consent forms. Ethical approval was obtained through the University of Wollongong Human Research Ethics Committee (HE14/330).

The study included a blend of centers in order to capture a variety of features such as the center indoor/outdoor routine; size and features of the physical environment; the number of 
children enrolled; and the use of indoor and outdoor environments, including the time that children had access to these environments.

Data for each center were collected over five consecutive days. Children wore an Actigraph GT3X+ (ActiGraph, Fort Walton Beach, FL) accelerometer for each day of attendance. The accelerometers were placed on a belt that was attached around the child's waist with the time they were put on and removed recorded. Accelerometers are widely used to objectively measure young children's physical activity and sedentary behavior and have been found to be a valid and reliable measurement tool for this population [16-18].

Accelerometer data were collected in 15 second epochs. This enabled the short bursts of activity characteristic of young children to be captured [18-21]. The time spent in SB, TPA (light(high) and, moderate- to vigorous-intensity physical activity) and MVPA were calculated using age-specific cut points ( $\mathrm{SB}<25$ counts $/ 15 \mathrm{~s}$; TPA $\geq 200$ counts $/ 15 \mathrm{~s}$; MVPA $>420$ counts/15s) [16-18]. Using ActiLife software [(ActiGraph, Pensacola, FL; version ActiLife (v6.12.1)], accelerometer data was cleaned using a 20min non-wear time, a minimum wear time of 180mins/day, and a minimum of one day [18].

Aspects of the centre, such as weather conditions throughout the day, any variations in typical practice, or special events were observed and recorded. The type of routine was collated from center documentation, such as the weekly program, as well as researcher observations during the week of data collection. The routine type was either structured (distinct periods of inside or outside time), or free (an aspect of a free-flowing routine where the children could independently select to be indoors or outdoors). For example, a routine of free-indooroutdoor meant that at the start of the day the children were able to access either indoor or outdoor play spaces, followed by all children playing indoors, and then all children playing outdoors. Given that such centers have aspects of a free routine these centers were classified 
as 'free routine' centers. Alternatively, centers that had a routine such as all children playing outdoors and then all children playing indoors were classified as 'structured' routine centers. Time spent outdoors was manually recorded by the researcher each day (i.e., when children were outdoors, the time was noted and when children returned inside, the time was also noted). In centers that offered a free routine, the time spent in outdoor environment was the 'potential' time available. The average minutes per day spent outdoors was then calculated for each center. The size of the yard was measured using a steel tape measure and was recorded in $\mathrm{m}^{2}$.

Data were analysed using STATA (Version 13 STATACorp LLC, College Station, Tx). Means and confidence intervals were calculated to describe the sample and show group differences. A multivariate linear regression analysis examined associations of the attributes of ECEC centers (routine, time outdoors, and size of outdoor environment) with the outcome variables, adjusting for the effects of center clustering and gender. All the variables were categorical - routine (free or structured); time outdoors ( $<4$ hours or $\geq 4$ hours); and size of the outdoor environment $\left(<400 \mathrm{~m}^{2}\right.$ or $\left.\geq 400 \mathrm{~m}^{2}\right)$. Similar to a previous study [22] the size of the outdoor environment was dichotomized using a median split into smaller $\left(<400 \mathrm{~m}^{2}\right)$ and larger $\left(\geq 400 \mathrm{~m}^{2}\right)$. An alpha level of 0.05 was used to determine statistical significance. Children's compliance with meeting physical activity recommendations while at the center was measured against the National Academy of Medicine Recommendations. This recommends that children accumulate an average of 15 minutes or more of TPA per hour [8].

\section{Results}

Physical activity data were collected from 490 children across 11 centers, however only in eight centers were physical activity data collected all day. As such, only data from eight 
centers (316 children) were included in the analyses for this study. Table 1 shows the sample characteristics. The average number of children measured in each service was 39.5 (range 2275; SD 16.81). Four centers were classified as having a free flowing routine, five centers spent four or more hours outside each day, and four centers had yard sizes that were greater than $400 \mathrm{~m}^{2}$. Girls spent significantly more time in SB compared to boys $(31.39 \mathrm{~min} / \mathrm{hr}$ vs $29.01 \mathrm{~min} / \mathrm{hr}, \mathrm{p}=0.006$ ), and boys were significantly more active than girls (TPA 17.22 mins/hr vs $14.89 \mathrm{~min} / \mathrm{hr}, \mathrm{p}=0.011$; and MVPA $9.46 \mathrm{~min} / \mathrm{hr}$ vs $7.79 \mathrm{mins} / \mathrm{hr}, \mathrm{p}=0.002)($ Table 2). A higher proportion of boys met the National Academy of Medicine Recommendations (62.03\% vs $48.73 \%$ respectively) (Table 3 ) compared to girls. 
Table.1: Characteristics of children, children's physical activity and ECEC centers

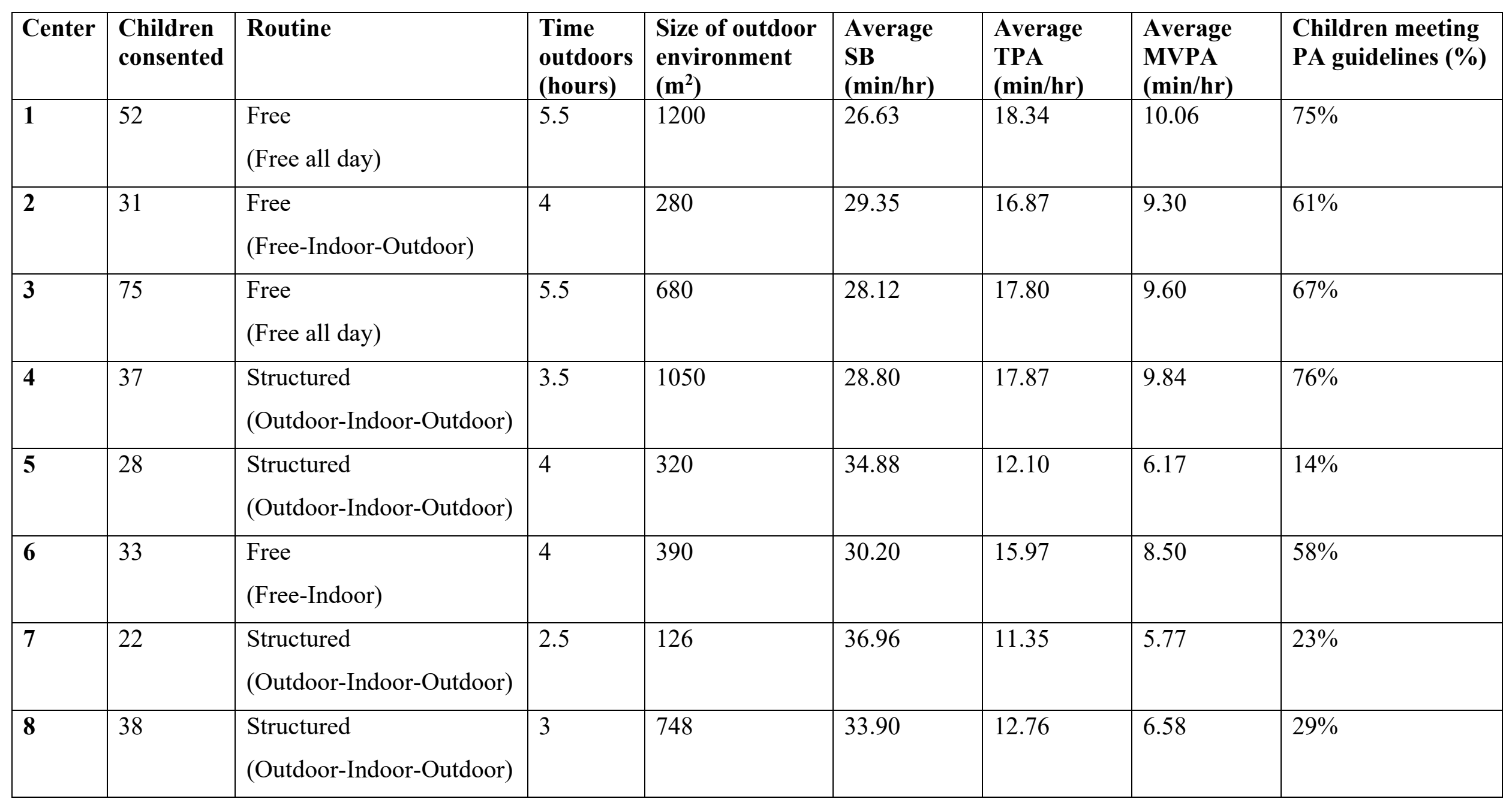


Note. Explanation of Routines: Structured routine (distinct periods of inside or outside time); Free routine (an aspect of a free-flowing routine where the children could independently select to be indoors or outdoors).

Free all day: children have access to indoor and outdoor environments all day; Free-Indoor-Outdoor: children have access to indoor and outdoor environments, followed by only indoors, and then only outdoors; Outdoor-Indoor-Outdoor: children are only outdoors, followed by only indoors, and then only outdoors; Free-Indoor: children have access to indoor and outdoor environments, followed by only indoors.

PA guidelines: National Academy of Medicine Recommendations (IOM, 2011). Recommends that children accumulate $\geq 15$ minutes of TPA per hour 
Girls spent significantly more time in SB compared to boys $(31.39 \mathrm{~min} / \mathrm{hr}$ vs $29.01 \mathrm{~min} / \mathrm{hr}$, $\mathrm{p}=0.006)$, and boys spent significantly more time in TPA and MVPA (17.22 $\mathrm{min} / \mathrm{hr}$ vs 14.89 $\min / \mathrm{hr}, \mathrm{p}=0.011 ; 9.46 \mathrm{~min} / \mathrm{hr}$ vs $7.79 \mathrm{~min} / \mathrm{hr}, \mathrm{p}=0.002$, respectively) compared to girls (Table 2). Approximately $62 \%$ of boys, compared to $48 \%$ of girls met the National Academy of Medicine recommendations for physical activity while in ECEC (Table 3).

Children from ECEC centers that facilitated a free routine spent significantly less time in SB compared with children from centers which facilitated a structured routine $(28.27 \mathrm{~min} / \mathrm{hr} \mathrm{vs}$ $33.15 \mathrm{~min} / \mathrm{hr}, \mathrm{p}=0.001)$. Children enrolled in free routine centers spent significantly more time in TPA and MVPA compared with children from structured routine centers $(7.99 \mathrm{~min} / \mathrm{hr}$ vs $6.57 \mathrm{~min} / \mathrm{hr}, \mathrm{p}=0.008 ; 9.49 \mathrm{~min} / \mathrm{hr}$ vs $7.31 \mathrm{~min} / \mathrm{hr}, \mathrm{p}=0.008$ respectively) (Table 2 ). More children enrolled in centers with free routines met the National Academy of Medicine recommendation compared with children from centers with a structured routine $(66.49 \% \mathrm{vs}$ 38.4\%) (Table 3). 
Table 2: Children's physical activity. Means, CI, adjusted difference, and P values.

\begin{tabular}{|c|c|c|c|c|}
\hline & & Mean mins/hr & $\begin{array}{l}\text { Adjusted difference, } \\
\text { 95\% CI }\end{array}$ & $P$ value \\
\hline \multicolumn{5}{|c|}{ Sedentary Behavior } \\
\hline \multirow[t]{2}{*}{ Sex } & Boys & $29.01(27.83,30.19)$ & \multirow{2}{*}{$\begin{array}{l}2.377457 \\
(0.93,3.82)\end{array}$} & \multirow[t]{2}{*}{0.006} \\
\hline & Girls & $31.39(30.28,32.50)$ & & \\
\hline \multirow[t]{2}{*}{ Routine } & Free & $28.27(27.27,29.27)$ & \multirow{2}{*}{$\begin{array}{l}4.221823 \\
(2.48,5.96)\end{array}$} & \multirow[t]{2}{*}{0.001} \\
\hline & Structured & $33.15(31.96,34.34)$ & & \\
\hline \multirow[t]{2}{*}{ Time outdoors } & $<4 \mathrm{hrs}$ & $32.65(31.16,34.14)$ & \multirow{2}{*}{$\begin{array}{l}-0.1467388 \\
(-1.23,0.93)\end{array}$} & \multirow[t]{2}{*}{0.757} \\
\hline & $\geq 4 \mathrm{hrs}$ & $29.12(28.17,30.06)$ & & \\
\hline \multirow{2}{*}{$\begin{array}{l}\text { Size of outdoor } \\
\text { environment }\end{array}$} & $<400 \mathrm{~m}^{2}$ & $32.42(31.0,33.86)$ & \multirow{2}{*}{$\begin{array}{l}-0.0052063 \\
(-0.01,-0.00)\end{array}$} & \multirow[t]{2}{*}{0.012} \\
\hline & $\geq 400 \mathrm{~m}^{2}$ & $28.94(28.0,29.9)$ & & \\
\hline \multicolumn{5}{|l|}{ TPA } \\
\hline \multirow[t]{2}{*}{ Sex } & Boys & $17.22(16.30,18.13)$ & \multirow{2}{*}{$\begin{array}{l}-0.6608422 \\
(-1.12,-0.20)\end{array}$} & \multirow[t]{2}{*}{0.011} \\
\hline & Girls & $14.89(14.08,15.71)$ & & \\
\hline \multirow[t]{2}{*}{ Routine } & Free & $7.99(7.70,8.29)$ & \multirow{2}{*}{$\begin{array}{l}-1.167068 \\
(-1.92,-0.41)\end{array}$} & \multirow[t]{2}{*}{0.008} \\
\hline & Structured & $6.57(6.23,6.91)$ & & \\
\hline \multirow[t]{2}{*}{ Time outdoors } & $<4 \mathrm{hrs}$ & $14.39(13.33,15.44)$ & \multirow{2}{*}{$\begin{array}{l}0.0881758 \\
(-0.40,0.58)\end{array}$} & \multirow[t]{2}{*}{0.684} \\
\hline & $\geq 4 \mathrm{hrs}$ & $16.79(16.04,17.54)$ & & \\
\hline \multirow{2}{*}{$\begin{array}{l}\text { Size of outdoor } \\
\text { environment }\end{array}$} & $<400 \mathrm{~m}^{2}$ & $14.37(13.35,15.4)$ & \multirow{2}{*}{$\begin{array}{l}0.001404 \\
(-0.00,0.00)\end{array}$} & \multirow[t]{2}{*}{0.072} \\
\hline & $\geq 400 \mathrm{~m}^{2}$ & $17(16.25,17.76)$ & & \\
\hline \multicolumn{5}{|l|}{ MVPA } \\
\hline \multirow[t]{2}{*}{ Sex } & Boys & $9.46(8.80,10.12)$ & \multirow{2}{*}{$\begin{array}{l}-1.662066 \\
(-2.51,-0.81)\end{array}$} & \multirow[t]{2}{*}{0.002} \\
\hline & Girls & $7.79(7.22,8.36)$ & & \\
\hline \multirow[t]{2}{*}{ Routine } & Free & $9.49(8.89,10.08)$ & \multirow{2}{*}{$\begin{array}{l}-2.045559 \\
(-3.36,-0.73)\end{array}$} & \multirow[t]{2}{*}{0.008} \\
\hline & Structured & $7.31(6.72,7.90)$ & & \\
\hline Time outdoors & $<4 \mathrm{hrs}$ & $7.64(6.92,8.36)$ & -0.396058 & 0.914 \\
\hline & $\geq 4 \mathrm{hrs}$ & $9.06(8.51,9.61)$ & $(-0.87,0.79)$ & \\
\hline Size of outdoor & $<400 \mathrm{~m}^{2}$ & $7.61(6.9,8.33)$ & 0.0025001 & 0.057 \\
\hline & $\geq 400 \mathrm{~m}^{2}$ & $9.19(8.64,9.75)$ & & \\
\hline
\end{tabular}

Note. $\mathrm{P}<0.05$; $\mathrm{CI}$ - confidence interval; bold - significant differences; TPA - total physical activity; MVPA - moderate- to vigorous-intensity physical activity; Structured routine 
(distinct periods of inside or outside time); Free routine (an aspect of a free-flowing routine where the children could independently select to be indoors or outdoors).

Table 3: Proportion of children meeting National Academy of Medicine Recommendation $(\geq 15 \mathrm{mins} \mathrm{TPA} / \mathrm{hr})[23]$

\begin{tabular}{|llllllll|}
\hline \multicolumn{2}{|c}{ Sex } & \multicolumn{2}{c}{ Routine } & \multicolumn{2}{c|}{ Time outdoors } & \multicolumn{2}{c|}{$\begin{array}{c}\text { Size of outdoor } \\
\text { environment }\end{array}$} \\
\hline Boys & Girls & Free & Structured & $\begin{array}{l}<\text { 4hrs } \\
\text { outdoors }\end{array}$ & $\begin{array}{l}\mathbf{2} \text { (4hrs } \\
\text { outdoors }\end{array}$ & $<\mathbf{4 0 0 m}^{\mathbf{2}}$ & $\mathbf{2 4 0 0 m ^ { 2 }}$ \\
\hline $62.03 \%$ & $48.73 \%$ & $66.49 \%$ & $38.4 \%$ & $45.36 \%$ & $59.82 \%$ & $41.23 \%$ & $63.37 \%$ \\
\hline
\end{tabular}

Note. Explanation of Routines: Structured routine (distinct periods of inside or outside time); Free routine (an aspect of a free-flowing routine where the children could independently select to be indoors or outdoors).

Children in ECEC centers with smaller outdoor environments $\left(<400 \mathrm{~m}^{2}\right)$ spent significantly more time in SB (32.42 $\mathrm{min} / \mathrm{hr}$ vs $28.94 \mathrm{~min} / \mathrm{hr}$, $\mathrm{p}=0.012)$ compared to children in centers with larger outdoor environments $\left(\geq 400 \mathrm{~m}^{2}\right)$ (Table 2$)$. In centers that had an outdoor environment that was more than $\geq 400 \mathrm{~m}^{2}$, the proportion of children meeting physical activity recommendations was over 22 percentage points greater $(41.23 \%$ vs $63.37 \%)$ than when the outdoor environment was $<400 \mathrm{~m}^{2}$ (Table 3 ).

No significant relationships between the time spent in ECEC center outdoor environment and physical activity were reported. However, data showed that more time in outdoor environments (i.e., $\geq 4 \mathrm{hrs}$ ) resulted in children spending less time in SB and more time in all intensities of physical activity (Table 2). Approximately $60 \%$ of children who spent $\geq 4$ hours 
outdoors met the National Academy of Medicine recommendations, while only $45 \%$ of children who spent $<4$ hours outdoors met this recommendation (Table 3).

\section{Discussion}

This study found significant relationships between children's physical activity and sedentary behavior and sex, and two environmental factors - routine and size of the outdoor environment. Boys were more active and more likely to meet physical activity recommendations compared with girls, all children were less sedentary and more active in centers that offered a free routine, and children were less sedentary in ECEC that had larger outdoor environments.

There was a consistent relationship between sedentary behavior, all levels of physical activity and sex. Boys were less sedentary and had higher levels of TPA and MVPA compared to girls. This is consistent with many other studies that also report a difference between the sedentary behavior and physical activity of girls and boys [24] [25] [26]. Studies have shown that girls prefer light intensity activities, such as social play with peers or dolls, or with art materials [27] and so creating physical and social environments - indoors and outdoors that reduce sedentary behavior and promote physical activity for girls is therefore important. This may include educators becoming actively involved with girls, as it is known that often girls will remain with educators, and are influenced by their behaviors [28]. Consideration of the experiences that are offered, such as dramatic play, or music and movement in both indoor and outdoor environments may also be strategies that will support higher levels of activity from girls. It has been reported that the amount of time girls spent indoors before going outdoors was inversely associated with their physical activity [29], and so adjusting the 
routine and scheduling of time that children have access to the outdoor environment is a strategy that may have a positive influence on the activity patterns for girls. Tandon et al.[5] suggest that more active play opportunities, and scheduling fewer sedentary expectations, such as mandated nap times, or even sedentary group times may be critical.

There are few known studies that have examined the association between type of routine (i.e., free vs structured) and children's physical activity in ECEC [10, 30]. Outcomes vary between these studies - one has shown no significant association between children's physical activity and free routine [30], and the other [10] showed an association between children having unrestricted access to outdoor areas and improvements in children's physical activity. The findings of the current study align with other studies that have shown scheduling regular periods of outdoor free-play has a positive influence on children's physical activity $[31,32]$. A free routine can replicate scheduling of play periods for children as the children freely move between indoor and outdoor environments.

Our findings may be explained by free routines offering choice and independence, elements that contribute to sustained engagement and uninterrupted time that afford quality experiences [33]. Cross-cultural research shows the value of child-initiated play, including the affordance of choice and independence across a range of developmental and curriculum areas [34]. The provision of a free routine replicates child initiated play. Quality active opportunities influence children's physical activity $[35,36]$ and so offering a free routine to increase the quality of experiences is important. There are considerations for educators prior to transitioning to a free routine, such as the provision of all learning experiences in the outdoor environment. Some learning experiences may be perceived as more suitable for indoor environments, for example literacy experiences and art experiences. It is important for educators to see the facilitation of such experiences in all environments. There is also 
potential for what is perceived as 'unfavourable' weather that may restrict opportunities for time in outdoor environments. It is evident in some curriculums, such as Bush Preschool, that weather conditions are not a barrier, and children are dressed and prepared according to the weather conditions (Elliot, et al., 2014). It is crucial, therefore that educators consider the benefits and modifications that may be required for this transition to a free routine, including understanding the value of outdoor environments, and the potential that increased time in these environments has for children's learning, development, health and well-being. Furthermore, as routines are a modifiable aspect of centers, with small changes there is potential for optimal impact, and importantly there is potential for these modifications to be facilitated across curriculums and countries. Facilitating an intervention that involves a less structured day and provision of a free routine may be a strategy for educators to increase children's physical activity and reduce children's sedentary behavior, and could be piloted relatively easily.

Free routines typically provide children with more opportunities to play in outdoor environments. In this study, three centers had less than 4 hours outdoors, and a common feature of these centers was a structured routine in which only one period of outdoor time was scheduled during the day (i.e., the routine was indoor-outdoor-indoor). In all but one of the remaining centers (four or more hours outdoors), there was a free aspect to the day.

A significant relationship was found between the size of the outdoor environment and children's sedentary behavior. This is congruent to other studies reporting that playground size is an important characteristic of children's physical activity in ECEC [37, 38]. Strategies that may counteract the effect of smaller outdoor environments on children's sedentary behavior and physical activity include increasing the amount of space afforded to each child. For example, scheduling play periods so that fewer children are in the environment at one 
time [39], offering a free routine which has the potential to distribute children between the indoor and outdoor environment, or accessing public spaces if available.

Children's sedentary behaviour was significantly associated with a free routine and the size of the outdoor environment. Although TPA increased when free routines were offered and the outdoor environment was larger, the associations were not significant nor as great as SB. This suggests that although children's PA will be influenced by the routine offered and the size of the outdoor environment, SB will be most influenced by these factors. As SB is just as important for children's health as PA, this has important practical implications. Centre routine is a modifiable aspect of ECEC centres and so future studies, programs and interventions need to focus on modifying the centre routine to have a positive impact on SB.

Although the relationships between sedentary behavior and physical activity and time spent in outdoor environments were non-significant, there was a positive trend for all intensities of physical activity. This is consistent with other studies [5,35]. An explanation for this may be that outdoor environments are important for children's physical activity [14], so therefore it is feasible to suggest that more time in these environments will promote an increase in physical activity across the day. Furthermore, the opportunity to have more time in outdoor environments may also result in children engaging in sustained experiences, such as a game of soccer knowing that the affordance of time will allow for uninterrupted play. Contrary to these findings, other studies $[39,40]$ have reported no relationship between time in outdoor environments and children's physical activity. These differences between studies may be due to the scheduling of time in outdoor environments. While the emphasis should be on adequate amounts of time in outdoor environments, the scheduling of time (e.g., regular periods rather than large blocks of time) in the outdoor environment may also be significant [32]. 
According to current National Academy of Medicine recommendations [8], children should spend at least 60-90 minutes each day in outdoor environments [41], however, there are barriers to accessing these environments and the time spent in them in ECEC settings. These barriers include the weather [40, 42]; educator perceptions of the environment such as supervision being paramount $[43,44]$; and/or the element of risk due to the unpredictable nature of the outdoor environment [45]. To ensure that children meet the current recommendations for physical activity and sedentary behavior while in ECEC, educators should reflect on current practices and promote quality time in outdoor environments. Outdoor environments have the potential to be a valuable space for learning, just as much as indoor environments are, and so intentionality is crucial. As time spent in an environment is a modifiable aspect of center practice that does not require additional skills, training or expensive resources to implement [46], promoting children's physical activity through increasing the time spent outdoors is highly feasible.

The present study found that just over half of the children met the National Academy of Medicine recommendations for physical activity while at ECEC (15mins of TPA/hr). This finding is similar to other studies in the US [47], UK [48] and Belgium [49]. The highest proportion of children meeting the recommendations were in centers that offered a free routine, compared with centers that offered a structured routine. The reasons for this may be that outdoor play opportunities are greater in centers that offer a free routine, and as a result children's physical activity increases. Consistent with other studies [40, 50-52], the proportion of boys meeting the National Academy of Medicine recommendations was greater than girls. This may be due to girls engaging in more sedentary contexts and experiences, such manipulative, dramatic, and fine motor play compared with boys [53]. Free routines may result in girls engaging in indoor environments more frequently than outdoor environments. 
There were several limitations of the study. The inclusion of only eight ECEC services limited variability in the size of the outdoor environment, and may have impacted the results. The small sample size may mean that the results may not be able to be generalised to the wider ECEC sector. The amount of time that physical activity data were collected varied between ECEC centers as did the duration of each child's day, particularly as ECEC center types and hours of operation varied. To overcome potential limitations due to this, researchers collected data the entire time that children were in the center. Additionally, children's physical activity and sedentary behavior were calculated as a proportion of time per hour. It is possible that the physical design of the ECEC centers, as well as number of children enrolled and child to educator ratios may have had an impact on the capacity to, and how well a center could accommodate a 'free' flowing routine. Information pertaining to the physical design, enrolments and ratios of the ECEC was not collected, but would be beneficial in future studies to understand reasons for, and barriers to facilitating specific routine types.

\section{Conclusion}

Children's physical activity and sedentary behavior in ECEC has the potential to have a positive influence on daily levels of activity. Developing effective practices and policies within these settings are crucial. This study illustrates the positive influence of modifiable factors in ECEC centers - routine and time spent in outdoor environments on children's physical activity and sedentary behavior. These findings are significant, as physical activity interventions are costly, time consuming and at times interruptive, and policies that support children's physical activity and sedentary behavior in these settings are limited. Modifying 
environmental factors such as routine and the amount of time spent in outdoor environments may be a preferable choice. 


\section{References}

1. Timmons, B.W., et al., Systematic review of physical activity and health in the early years (aged 0-4 years). Applied Physiology, Nutrition, and Metabolism, 2012. 37(4): p. 773-792.

2. Jones, R.A., et al., Tracking physical activity and sedentary behavior in childhood: a systematic review. Am J Prev Med, 2013. 44(6): p. 651-8.

3. OECD, OECD Family Database. PF3.2: Enrolment in childcare and pre-schools: OECD - Social Policy Division - Directorate of Employment, Labour and Social Affairs; 2014. 2014.

4. Ward, S., et al., Systematic review of the relationship between childcare educators' practices and preschoolers' physical activity and eating behaviors. Obes Rev, 2015. 16(12): p. 1055-70.

5. Tandon, P.S., B.E. Saelens, and D.A. Christakis, Active Play Opportunities at Child Care. Pediatrics, 2015.

6. Ellis, Y.G., et al., Sedentary time, physical activity and compliance with IOM recommendations in young children at childcare. Prev Med Rep, 2017. 7(C): p. 221-226.

7. Pate, R.R., et al., Prevalence of compliance with a new physical activity guideline for preschool-age children. Childhood Obesity, 2015. 11(4): p. 415-420.

8. Institute of Medicine . Retrieved Feb 2, f.h.i.e.R.E.-C.-O.-P.-P.R.a., Early Childhood Obesity Prevention Policies Institute Of Medicine. 2011.

9. Tonge, K.L., R.A. Jones, and A.D. Okely, Correlates of children's objectively measured physical activity and sedentary behavior in early childhood education and care services: A systematic review. Preventive Medicine, 2016. 89: p. 129-139.

10. Hesketh, K.R. and E.M. Sluijs, Features of the UK childcare environment and associations with preschooler's in-care physical activity. Prev Med Rep, 2016. 3.

11. Bento, G. and G. Dias, The importance of outdoor play for young children's healthy development. Porto Biomedical Journal, 2017. 2(5): p. 157-160.

12. Gagne, C. and I. Harnois, The contribution of psychosocial variables in explaining preschoolers' physical activity. Health Psychology, 2013. 32(6): p. 657-665.

13. Wolfenden, L., et al., Physical activity policies and practices of childcare centers in Australia. Journal of Paediatrics and Child Health, 2011. 47(3): p. 73-76.

14. Raustorp, A., et al., Accelerometer measured level of physical activity indoors and outdoors during preschool time in Sweden and the United States. Journal of Physical Activity \& Health, 2012. 9(6): p. 801-808.

15. Dowda, M., et al., Influences of Preschool Policies and Practices on Children's Physical Activity. Journal of Community Health: The Publication for Health Promotion and Disease Prevention, 2004. 29(3): p. 183-196.

16. Pate, R.R., et al., Validation and calibration of an accelerometer in preschool children. Obesity (Silver Spring), 2006. 14(11): p. 2000-6.

17. Sirard, J.R., et al., Calibration and evaluation of an objective measure of physical activity in preschool children. JPAH, 2005. 2.

18. Cliff, D.P., et al., Relationships Between Fundamental Movement Skills and Objectively Measured Physical Activity in Preschool Children. Pediatric Exercise Science, 2009. 21(4): p. 436-449.

19. Reilly, J.J., Physical activity, sedentary behavior and energy balance in the preschool child: opportunities for early obesity prevention: Symposium on 'Behavioral nutrition and energy balance in the young'. Proceedings of the Nutrition Society, 2008. 67(3): p. 317-325.

20. Ward, D.S., et al., Accelerometer use in physical activity: best practices and research recommendations. Medicine And Science In Sports And Exercise, 2005. 37(11 Suppl): p. S582-S588.

21. Nilsson, A., et al., Assessing physical activity among children with accelerometers using different time sampling intervals and placements. Pediatr Exerc Sci, 2002. 14(1): p. 87-96. 
22. Sugiyama, T., et al., Attributes of child care centers and outdoor play areas associated with preschoolers' physical activity and sedentary behavior. Environ Behav, 2012. 44.

23. Medicine, I.o., Early Childhood Obesity Prevention Policies, ed. L.L. Birch, L. Parker, and A. Burns. 2011, Washington, DC: The National Academies Press. 202.

24. Copeland, K.A., J.C. Khoury, and H.J. Kalkwarf, Child Care Center characteristics associated with preschoolers' physical activity. Am J Prev Med, 2016. 50.

25. Henderson, K.E., et al., Environmental factors associated with physical activity in childcare centers. Int J Behav Nutr Phys Act, 2015. 12.

26. Soini, A., et al., A comparison of physical activity levels in childcare contexts among Finnish and Dutch three-year-olds. European Early Childhood Education Research Journal, 2016. 24(5): p. 775-786.

27. Barbu, S., G. Cabanes, and G. Maner-Idrissi, Boys and Girls on the Playground: Sex Differences in Social Development Are Not Stable across Early Childhood. PloS one, 2011. 6: p. e16407.

28. Wang, C., et al., The combined effects of teacher-child and peer relationships on children's social-emotional adjustment. Journal of School Psychology, 2016. 59: p. 1-11.

29. Hinkley, T., et al., Preschool and childcare center characteristics associated with children's physical activity during care hours: an observational study. International Journal of Behavioral Nutrition and Physical Activity, 2016. 13(1): p. 117.

30. Lecathelinais, C., et al., Efficacy of a free-play intervention to increase physical activity during childcare: a randomized controlled trial. Health Education Research, 2018. 34(1): p. 84-97.

31. Patricia, T., et al., Impact of the Supporting Physical Activity in the Childcare Environment (SPACE) intervention on preschoolers' physical activity levels and sedentary time: a singleblind cluster randomized controlled trial. International Journal of Behavioral Nutrition and Physical Activity, Vol 14, Iss 1, Pp 1-11 (2017), 2017(1): p. 1.

32. Lubna Abdul, R., et al., Impact of scheduling multiple outdoor free-play periods in childcare on child moderate-to-vigorous physical activity: a cluster randomised trial. International Journal of Behavioral Nutrition and Physical Activity, Vol 15, Iss 1, Pp 1-12 (2018), 2018(1): p. 1.

33. Siraj-Blatchford, I., Conceptualising progression in the pedagogy of play and sustained shared thinking in early childhood education: A Vygotskian perspective. Educational and Child Psychology, 2009. 26(2): p. 77-89.

34. Hedges, H., S.S. Peterson, and G. Wajskop, Modes of play in early childhood curricular documents in Brazil, New Zealand and Ontario. International Journal of Play, 2018. 7(1): p. 11-26.

35. Bower, J.K., et al., The childcare environment and children's physical activity. American journal of preventive medicine, 2008. 34(1): p. 23-29.

36. Gubbels, J.S., S.P. Kremers, and D.H. Kann, Interaction between physical environment, social environment, and child characteristics in determining physical activity at child care. Health Psychol, 2011. 30.

37. Cardon, G., et al., The contribution of preschool playground factors in explaining children's physical activity during recess. International Journal of Behavioral Nutrition and Physical Activity, 2008. 5(1): p. 11.

38. Boldemann, C., M. Blennow, and H. Dal, Impact of preschool environment upon children's physical activity and sun exposure. Prev Med, 2006. 42.

39. Dowda, M., Brown, W.H., Mclver, K.L., Pfieffer, K.A., O'Neill, C.L., Pate, A., \& Pate, R.R., Policies and Characteristics of the Preschool Environment and Physical Activity of Young Children

Pediatrics, 2009. 123(2): p. 261-266.

40. Olesen, L.G., Kristensen, P.L., Korsholm, L., \& Froberg, K., Physical Activity in Children Attending Preschools. Pediatrics, 2013. 132(5): p. 1310-1318. 
41. Copeland, B.M., Risk factors for childhood obesity in head start children. Dissertation Abstracts International: Section B: The Sciences and Engineering, 2012. 73(6-B): p. 3540.

42. Edwards, N.M., et al., Outdoor temperature, precipitation, and wind speed affect physical activity levels in children: A longitudinal cohort study. Journal of Physical Activity and Health, 2015. 12(8): p. 1074-1081.

43. Coleman, B.D., J.E. , Factors that limit and enable preschool-aged children's physical activity on child care center playgrounds. Journal of Early Childhood Research, 2013. 11(3): p. 203221.

44. Temple, V. and J.P. O'Connor, Constraints and facilitators for physical activity in family day care. Australian Journal of Early Childhood, 2005. 30(4): p. 1-9.

45. Little, H. and S. Wyver, Outdoor play: Does avoiding the risks reduce the benefits? Australian Journal of Early Childhood, 2008. 33(2): p. 33-40.

46. Pagnini D, W.R., The weight of opinion: the early childhood sector's perceptions about childhood overweight and obesity PANDORA electronic collection, ed. D. Pagnini, et al. 2006, Sydney, N.S.W: NSW Center for Overweight and Obesity, School of Public Health, University of Sydney.

47. Brown, W.H., et al., Social and Environmental Factors Associated With Preschoolers Nonsedentary Physical Activity. Child Development, 2009. 80(1): p. 45-45.

48. Reilly, J.J., et al., Physical activity to prevent obesity in young children: cluster randomised controlled trial. BMJ, 2006. 333.

49. Cardon, G. and I. Bourdeaudhuij, Are preschool children active enough? Objectively measured physical activity levels. Res Q Exerc Sport, 2008. 79.

50. Pate, R.R., et al., Directly Observed Physical Activity Levels in Preschool Children. Journal of School Health, 2008. 78(8): p. 438-444.

51. Nicaise, V., D. Kahan, and J.F. Sallis, Correlates of moderate-to-vigorous physical activity among preschoolers during unstructured outdoor play periods. Prev Med, 2011. 53(4-5): p. 309-15.

52. Stephens, R.L., et al., Relationship Between Child Care Centers' Compliance With Physical Activity Regulations and Children's Physical Activity, New York City, 2010. PREVENTING CHRONIC DISEASE, 2014. 11: p. E179.

53. Miller, E., Children's Perceptions of Play Experiences and Play Preferences: A Qualitative Study. The American journal of occupational therapy, 2008. 62(4): p. 407-415. 